\title{
Sob o signo da diversidade: contribuições para o debate acadêmico de questões emergentes no mundo atual
}

Atualmente, a Paideia está consolidada como uma revista que prima pela publicação de artigos científicos de elevada qualidade e que contribuem com o avanço do conhecimento em Psicologia, Educação e áreas afins.

Este fascículo 20, número 45, da Paideia apresenta a pluralidade de temáticas, abordagens metodológicas e origem dos pesquisadores que caracteriza a política editorial da revista, sempre atenta à produção de conhecimento original e ao debate acadêmico de questões emergentes na contemporaneidade.

O fascículo é aberto com o trabalho Paideia: relatório de gestão - 2009, de Manoel Antônio dos Santos, no qual são apresentados os indicadores que permitem mapear, de modo objetivo e com riqueza de pormenores, os meandros do processo editorial da Paideia no último ano. Além de apresentar um levantamento estatístico, esse relatório dá transparência à sistemática de arbitragem utilizada pela revista para a qualificação dos manuscritos submetidos à avaliação.

Os artigos recobrem um amplo e diversificado leque de temas que marcam o debate atual de ideias, a saber: a vida familiar na perspectiva de judeus e não judeus, as representações sociais de povos indígenas, estilos de gerenciamento, diferenças de gênero, perspectivas de futuro em adolescentes, ansiedade frente ao vestibular, riscos percebidos no contexto da intoxicação por chumbo, estresse e qualidade de vida, o imaginário das pessoas idosas, princípios orientadores da formação humana, representação psíquica e teoria da linguagem em Freud, produção de desenhos em grupo e aplicação do método de Rorschach na esquizofrenia, gravidez na adolescência.

Tendo como escopo o enriquecimento do debate crítico sobre a pesquisa em Psicologia e Educação, a seção destinada aos artigos é aberta com o estudo de autoria compartilhada Brasil-Reino Unido, intitulado Influência social na vida familiar: grupos étnicos e relações interculturais, de Edson Alves de Souza Filho, da Universidade Federal do Rio de Janeiro e Angel Beldarrain-Durandegui, da Loughborough University, do Reino Unido, que analisam as lembranças de jovens judeus e não judeus, visando inferir padrões de influência social adotados por pais e antepassados. Os autores concluem que os modelos de influência mais adotados nos ambientes familiares foram diferenciados entre os grupos. Concluíram que os judeus tenderam, principalmente, à formação/afirmação individual e identitária cultural/religiosa. Já os não judeus mostraram-se mais inclinados a se lembrarem de aspectos relacionais da família, com menor focalização nos aspectos grupais socioculturais tanto de si quanto dos outros.
A segunda contribuição, de autoria de Marcus Eugênio Oliveira Lima e Alan Magno Matos de Almeida, da Universidade Federal de Sergipe, intitulada Representações sociais construídas sobre os índios em Sergipe: ausência e invisibilização, versa sobre as representações sociais construídas pelos sergipanos sobre os povos indígenas. Foram entrevistados 378 participantes. As conclusões indicam que, para muitos dos pesquisados, os índios existem apenas como uma ausência ou, ainda, de um modo naturalizado, como reminiscências fenotípicas e culturais de uma história de 500 anos de violência e extermínio.

Na sequência, o artigo Influência dos valores organizacionais sobre estilos de gerenciamento em empresas de pequeno porte, de Eliana Elisabete Moreira Gosendo, do Centro Universitário UNIERO de Brasília, e Cláudio Vaz Torres, da Universidade de Brasília, identifica a hierarquia dos valores organizacionais e investiga os estilos de gerenciamento e a influência dos valores organizacionais nos estilos de gerenciamento. Trata-se de um estudo pioneiro que objetiva estudar e desvendar a realidade das micro e pequenas organizações, bem como as percepções de pessoas com baixo nível de escolaridade.

Dando continuidade às pesquisas relativas à psicologia organizacional, o artigo Diferenças de gênero e valores relativos ao trabalho, de Margareth Ribeiro Machado Santos e Silva, da Faculdade Estácio de Sá de Goiás e de Daniela Sacramento Zanini, da Pontifícia Universidade Católica de Goiás, discute um aspecto pouco explorado no âmbito da psicologia organizacional, que é a questão do gênero e valores. Considerando que os valores permeiam todos os papéis desempenhados por homens e mulheres, os autores ressaltam a importância de intervenções que objetivem a redução do sexismo no âmbito do trabalho.

$\mathrm{O}$ artigo Estudo comparativo sobre a perspectiva de futuro dos estudantes de escolas públicas e privadas, de autoria de Isabel Cristina Vasconcelos de Oliveira, da Universidade Federal do Rio Grande do Norte, e de Ana Alayde Werba Saldanha, da Universidade Federal da Paraíba, é uma investigação exploratória realizada com 296 estudantes do ensino fundamental e médio de instituições públicas e privadas, que comparou as expectativas dos estudantes em relação ao futuro. Conclui-se que os estudantes de escolas públicas e privadas apresentam aspirações similares quanto ao modo como idealizam seu futuro.

Também investigando estudantes de ensino médio, o artigo Ansiedade dos estudantes diante da expectativa do exame vestibular, de Adriana Benevides Soares, da 
Universidade Salgado de Oliveira-RJ, e Janaína Siqueira Rodrigues Martins, da Universidade Gama Filho-RJ, investigou a ansiedade dos jovens estudantes em relação ao vestibular. Os resultados mostraram diferença estatisticamente significativa em relação ao gênero, sendo que as mulheres foram as mais ansiosas.

A contribuição seguinte, Percepção de risco de pessoas envolvidas com intoxicação por chumbo, de Lígia Ebner Melchiori, Patrícia Kusumi, Olga Maria Piazentin Rolim Rodrigues, Tânia Gracy do Valle, Vera Lúcia Messias Fialho Capellini e Carmem Maria Bueno Neme, da Universidade Estadual Paulista Júlio de Mesquita Filho, Bauru-SP, teve por objetivo verificar a percepção que as crianças e seus responsáveis têm sobre a intoxicação por chumbo, por meio de entrevistas. Frente aos resultados, que indicaram a falta de compreensão de várias dimensões do fenômeno, as autoras sugerem a implementação de políticas de saúde pública adequadas e efetivas para o atendimento a esse segmento vulnerável da população.

Na sequência, o artigo Stress e qualidade de vida: influência de algumas variáveis pessoais, de autoria de Maria Angélica Sadir, Márcia Maria Bignotto e Marilda Emmanuel Novaes Lipp, da Pontifícia Universidade Católica de Campinas, verificou as variáveis pessoais que interferem nos níveis de stress e qualidade de vida de uma amostra de 106 adultos. Os resultados indicaram uma associação significativa entre stress e gênero, mas não entre o cargo exercido e o nível de stress aferido.

$\mathrm{O}$ artigo Imaginário e envelhecimento: imagens simbólicas de três nonagenários, de autoria de Walter José Martins Migliorini, da Universidade Estadual Paulista Júlio de Mesquita Filho, Araraquara-SP, investigou as imagens simbólicas produzidas por pessoas idosas. $\mathrm{O}$ estudo analisa o material derivado de estórias, grafismos, sonhos, devaneios e lembranças de pessoas idosas, de acordo com a teoria do imaginário de Gilbert Durand. Os resultados indicam ausência de uma estrutura do imaginário recorrente, presença de uma exuberante imaginação simbólica, permeabilidade entre conteúdos da memória e imaginação, além de criatividade e intensos processos afetivos.

O próximo artigo, de natureza teórica, Princípios orientadores da formação humana: dimensão normativa da educação, de autoria de José Policarpo Junior e Maria Lucicleide Falcão de Melo Rodrigues, da Universidade Federal de Pernambuco, promove uma reflexão sobre princípios que fundamentam a natureza da educação. Os autores reforçam a importância, no âmbito educativo, da clareza sobre os princípios que configuram a natureza do educar.

Também de cunho teórico, o artigo Representação psíquica e teoria da linguagem nos textos iniciais freudianos: um estudo da monografia sobre as afasias, de autoria de Érico Bruno Viana Campos, aborda o tema da representação psíquica e sua vinculação com a linguagem na obra inicial de Freud. O autor defende que a teoria da representação, desde o início, está situada para além da estrutura da linguagem, pois essa abordagem é secundária à investigação do sentido das produções do inconsciente e das pulsões.

Na sequência, o artigo Ateliê de desenho e Rorschach: Estudo fenômeno-estrutural, de Jacqueline Santoantonio e Andrés Eduardo Aguirre Antúnez, da Universidade Federal de São Paulo, analisa a produção de desenhos em grupo e aplicação do método de Rorschach ao longo do tratamento de um paciente portador de esquizofrenia, utilizando como referencial o método fenômeno-estrutural. Os autores concluem que a aplicação desses instrumentos contribuem com a tarefa diagnóstica e de acompanhamento da evolução de pacientes psicóticos.

Encerrando a seção de artigos, o estudo Gravidez na adolescência: um olhar sobre um fenômeno complexo, de Ana Cristina Garcia Dias, da Universidade Federal de Santa Maria, e Marco Antônio Pereira Teixeira, da Universidade Federal do Rio Grande do Sul, apresenta uma revisão crítica da literatura. Os resultados indicam que a gravidez na adolescência não é um fenômeno homogêneo e depende do contexto social em que a adolescente vive. Os autores reforçam a necessidade de intervenções voltadas à saúde sexual e reprodutiva dos adolescentes.

Por fim, a última seção dedica-se à resenha Humanismo e Fenomenologia: na psicologia, na psicopatologia e na psicoterapia, de José Célio Freire, da Universidade Federal do Ceará. O autor apresenta o instigante livro Clínica humanista-fenomenológica: Estudos em psicoterapia e psicopatologia crítica, de Virgínia Moreira, publicado pela editora Annablume em 2009.

Este número se encerra com as Normas de Publicação. É sempre oportuno lembrar que a Paideia é uma publicação quadrimestral disponível integralmente na Biblioteca Científica Eletrônica Online - SciELO Brasil, site www.scielo.br/rlae.

Lembramos que o período para submissões de manuscritos à revista é aberto o ano todo. Os interessados em contribuir devem consultar as normas de publicação disponibilizadas no site da SciELO. Lembramos que a Paideia está operacionalizando a mudança para o sistema Submission da SciELO, de modo a implementar a submissão online.

Esperamos que os leitores se sintam motivados a empreenderem uma leitura profícua das contribuições disponibilizadas por este fascículo.
Manoel Antônio dos Santos Editor 